\title{
Internal Waves in the Strait of Messina Studied by a Numerical Model and Synthetic Aperture Radar Images from the ERS 1/2 Satellites
}

\author{
Peter Brandt, Angelo Rubino, Werner Alpers, and Jan O. Backhaus \\ Institut für Meereskunde, Universität Hamburg, Hamburg, Germany
}

(Manuscript received 4 April 1996, in final form 3 September 1996)

\begin{abstract}
A new numerical two-layer model is presented, which describes the generation of internal tidal bores and their disintegration into internal solitary waves in the Strait of Messina. This model is used to explain observations made by the synthetic aperture radar (SAR) from the European Remote Sensing satellites ERS 1 and ERS 2. The analysis of available ERS 1/2 SAR data of the Strait of Messina and adjacent sea areas show that 1) northward as well as southward propagating internal waves are generated in the Strait of Messina, 2) southward propagating internal waves are observed more frequently than northward propagating internal waves, 3) sea surface manifestations of southward as well as northward propagating internal waves are stronger during periods where a strong seasonal thermocline is known to be present, 4) southward propagating internal bores are released from the sill between 1 and 5 hours after maximum northward tidal flow and northward propagating internal bores are released between 2 and 6 hours after maximum southward tidal flow, and 5) the spatial separation between the first two internal solitary waves of southward propagating wave trains is smaller in the period from July to September than in the period from October to June.

The numerical two-layer model is a composite of two models consisting of 1) a hydrostatic "generation model," which describes the dynamics of the water masses in the region close to the strait's sill, where internal bores are generated, and 2) a weakly nonhydrostatic "propagation model," which describes the dynamics of the water masses outside of the sill region where internal bores may disintegrate into internal solitary waves. Due to a technique for movable lateral boundaries, the generation model is capable of simulating the dynamics of a lower layer that may intersect the bottom topography. The proposed generation-propagation model depends on one space variable only, but it retains several features of a fully three-dimensional model by including a realistic channel depth and a realistic channel width. It is driven by semidiurnal tidal oscillations of the sea level at the two open boundaries of the model domain.

Numerical simulations elucidate several observed characteristics of the internal wave field in the Strait of Messina, such as north-south asymmetry, times of release of the internal bores from the strait's sill, propagation speeds, and spatial separations between the first two solitary waves of internal wave trains.
\end{abstract}

\section{Introduction}

The study of flow of stratified fluids over topography has received a great deal of attention in the last decades. In the ocean, as well as in the atmosphere, the interaction of flows of stratified fluids with obstacles gives rise to a great variety of internal disturbances. In particular, oceanic internal waves are generated when tidal flow interacts with topographic features like sills, continental slopes, or sand banks.

Among the earliest observations of tidally generated oceanic internal waves are those by Ziegenbein (1969) in the Strait of Gibraltar and by Halpern (1970) in Massachusetts Bay. Later measurements demonstrated the existence of tidally generated internal waves in numer-

Corresponding author address: Peter Brandt, Institut für Meereskunde, Universität Hamburg, Troplowitzstr. 7, D-22529 Hamburg, Germany.

E-mail: brandt@ifm.uni-hamburg.de ous other locations in the world's ocean, for example, in the Andaman Sea (Osborne and Burch 1980), in the New York Bight (Liu 1988), in the Gulf of California (Fu and Holt 1984), on the Scotian Shelf (Sandstrom and Elliot 1984), in the Sulu Sea (Apel et al. 1985), in the Celtic Sea (Pingree and Mardell 1985), and in the Bay of Biscay (New and Pingree 1992). Among the different measurement techniques, remote sensing has proven to be a powerful tool for studying the dynamics of internal waves (Apel et al. 1975; Watson and Robinson 1990; Richez 1994; Brandt et al. 1996). For example, in 1978, the existence of internal waves generated in the Strait of Messina was first inferred from a synthetic aperture radar (SAR) image acquired from the American Seasat satellite (Alpers and Salusti 1983).

This large amount of oceanic observations finds its counterpart in a great number of laboratory experiments and theoretical studies devoted to understanding the general nature of the flow of stratified fluids over topography. The generation of nonlinear internal disturbances in a two-layer system due to stationary flows 
over topography was studied, for example, by Long (1954) and Baines (1984), who identified different flow regimes depending on the system's Froude number. Theoretical and experimental studies on the generation mechanism of internal waves by the interaction of tidal flow with topography were carried out, among others, by Maxworthy (1979, 1980), Lansing and Maxworthy (1984), Hibiya (1986, 1990), and Renouard and Baey (1993). When modeling the generation and propagation of internal solitary waves, one has, in general, to separate the problem into a "generation phase," for which the hydrostatic approximation is usually applied (Hibiya 1986, 1990; Longo et al. 1992), and a "propagation phase," for which a nonhydrostatic description is required (Pierini 1989; Gerkema and Zimmerman 1995; Brandt et al. 1996). A comprehensive summary of theories and observations describing internal solitary waves in the ocean can be found in Apel et al. (1995).

In this paper we study the generation and propagation of internal solitary waves in the Strait of Messina. In this strait, which is a narrow channel separating the island of Sicily from the Italian peninsula, strong tidal currents occur, which interact with the shallow sill located in its center. In order to describe the dynamics of the water masses in the strait, we developed a two-layer numerical model. The model is a composite of two models consisting of 1) a hydrostatic model equipped with movable lateral boundaries, which describes the dynamics of the water masses in the region close to the strait's sill where the internal bores are generated and 2) a weakly nonhydrostatic model, which describes the dynamics of the water masses outside of the sill region where the internal bores may disintegrate into internal solitary waves. A coupling between the two models allows for a joint description of both generation and far-field propagation of the internal waves in the Strait of Messina. Previous models describing the dynamics of the water mass in this strait have either focused on the tidal forcing of the water mass interface near the strait's sill (Hopkins et al. 1984) or on the tidally induced circulation (Del Ricco 1982; Androsov et al. 1994), but never on the internal wave dynamics.

The outline of the paper is as follows: In section 2 the hydrodynamics of the Strait of Messina is described. Recent observations of internal solitary waves in the Strait of Messina are summarized and results from the analysis of synthetic aperture radar imagery acquired over the Strait of Messina and adjacent sea areas by the European Remote Sensing satellites ERS1/2 are presented in section 3 . In section 4 the two numerical models are described, and in section 5 their validity is tested by comparing results of these models with results of other models and with laboratory data. Numerical simulations carried out with realistic bottom topography are presented in section 6 . In section 7 , the results of the simulations are summarized and compared with radar signatures of internal waves that can be delineated on ERS1/2 SAR images of the Strait of Messina and adjacent sea areas. Finally, in section 8 the results of this investigation are summarized and conclusions are presented.

\section{Hydrodynamics of the Strait of Messina}

The Strait of Messina separates the Italian Peninsula from the Italian island of Sicily and connects the Tyrrhenian Sea in the north with the Ionian Sea in the south. The strait is a narrow channel, whose smallest crosssectional area is $0.3 \mathrm{~km}^{2}$ in the sill region. There, the mean water depth is $80 \mathrm{~m}$. While in the southern part of the strait the water depth increases rapidly (a depth of $800 \mathrm{~m}$ is encountered approximately $15 \mathrm{~km}$ south of the sill), in the northern part it increases more gently (a depth of $400 \mathrm{~m}$ is encountered approximately $15 \mathrm{~km}$ north of the sill). Throughout the year, two different water masses are present in the Strait of Messina: the Tyrrhenian surface water (TSW) and the colder and saltier Levantine Intermediate Water (LIW). In the vicinity of the Strait of Messina these water masses are separated at a depth of about $150 \mathrm{~m}$ (Vercelli 1925). During most of the year, a seasonal thermocline is also present in the strait. Across this interface the difference in the water density is, in general, much larger than across the interface between the LIW and TSW. Although tidal displacements are very small in the Mediterranean Sea (of the order of $10 \mathrm{~cm}$ ), large gradients of tidal displacements are present in the Strait of Messina, because the predominantly semidiurnal tides north and south of the strait are approximately in phase opposition. Due to the phase opposition of the tides and due to topographic constrictions, the current velocities in the Strait of Messina can attain values as high as $3.0 \mathrm{~m} \mathrm{~s}^{-1}$ in the sill region. There is also a weak mean exchange flow through the strait; while the mean flow of the surface layer is directed toward the Ionian Sea with a velocity of approximately $0.10 \mathrm{~m} \mathrm{~s}^{-1}$, the mean flow in the lower layer is directed toward the Tyrrhenian Sea with a velocity of approximately $0.13 \mathrm{~m} \mathrm{~s}^{-1}$. This mean exchange can strongly fluctuate, depending on wind and air pressure changes. Velocities of the mean flow up to $0.5 \mathrm{~m}$ $\mathrm{s}^{-1}$ may be present at the sill (Vercelli 1925; Defant 1940, 1961). For more detailed information on the hydrodynamics of the Strait of Messina the reader is referred to the review paper of Bignami and Salusti (1990).

\section{Observations of internal solitary waves}

\section{a. Summary of previous observations}

The first observation of internal solitary waves generated in the Strait of Messina was made by the SAR aboard the American Seasat satellite on 15 September 1978. The three rings visible on the Seasat SAR image in the Tyrrhenian Sea north of the strait were interpreted as sea surface manifestations of a train of internal solitary waves propagating northward (Alpers and Salusti 
1983). In the following years, oceanographic campaigns were carried out to measure internal solitary waves north and south of the strait. In November 1980 two northward propagating internal wave trains were detected in temperature data records at a position $25 \mathrm{~km}$ north of the strait. The time lag between the time of arrival of the two wave trains at this position was $11 \mathrm{~h} 30 \mathrm{~min}$, which agrees well to the time interval of $11 \mathrm{~h} 22 \mathrm{~min}$ between the two successive tidal flow reversals at the strait's sill, identified as the release times of the observed internal bores from the sill (Alpers and Salusti 1983; Griffa et al. 1986). During an oceanographic cruise from May to June 1982, Sapia and Salusti (1987) detected in temperature data records two trains of internal solitary waves north of the strait. During this cruise oceanographic measurements were also carried out south of the strait, which revealed the existence of large amplitude isolated signals in the temperature data records south of the sill and as far as to the coast of Syracuse. By using temperature sensors and a KODEN fish finder, Di Sarra et al. (1987) observed a 100-m deep depression of the interface between the water masses in the zone immediately south of the sill. The first observation of a well developed internal wave train south of the sill was made by the thematic mapper (TM) aboard the Landsat satellite (Artale et al. 1990). In October 1987 Nicolò and Salusti (1991) also observed in temperature data records three large amplitude internal wave trains south of the sill.

\section{b. Synthetic aperture radar data from the ERS 1/2}

Internal waves become visible on radar images because they are associated with variable surface currents that modify the surface roughness patterns via currentwave interaction. The radar is a surface roughness sensor: the rougher the sea surface, the higher the normalized radar cross section (NRCS) and thus the brighter the image intensity. According to a first-order radar imaging theory, the relative variation of NRCS associated with internal waves $\Delta \sigma / \sigma_{0}$ is related to the gradient of the surface velocity $\partial u / \partial x$ by

$$
\frac{\Delta \sigma}{\sigma_{0}}=-A \frac{\partial u}{\partial x},
$$

where $A$ denotes a positive function that depends, among others, on radar wavelength, radar incidence angle, angle between the radar look direction and the propagation direction of the internal wave, azimuth angle, and wind velocity at the sea surface (Alpers 1985). For a linear SAR system, $\Delta \sigma / \sigma_{0}$ is equal to the relative variation of the SAR image intensity (modulation depth). Thus, to first order, the variation of the image intensity is proportional to the gradient of the surface velocity or, as we will call it in the following, to the surface convergence, $-\partial u / \partial x$.

From 1991 to 1995 , several SAR images have been acquired by the European Remote Sensing satellites ERS 1

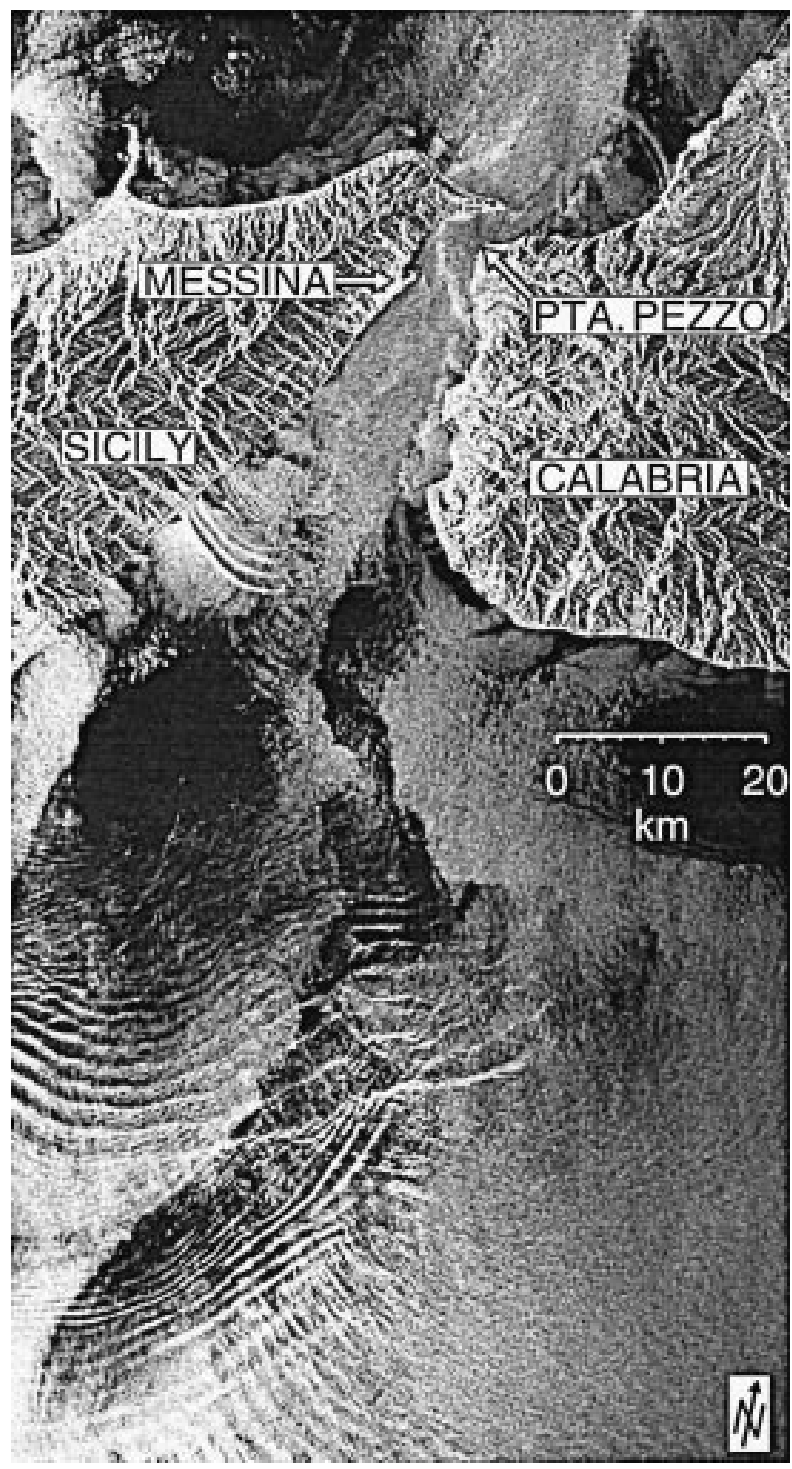

FIG. 1. ERS 1 SAR image of the Strait of Messina acquired at 2113 UTC 17 August 1995, 12 h 26 min after maximum northward tidal flow at Punta Pezzo. The image shows sea surface manifestations of three internal wave trains propagating southward and one propagating northward.

and ERS 2 over the Strait of Messina and the adjacent sea areas. In this investigation, we have analyzed ERS 1/2 SAR images acquired during 160 satellite overflights over the sea areas north and south of the sill. On SAR images acquired during 77 satellite overflights, sea surface manifestations of internal waves could be delineated. Figure 1 shows an ERS 1 SAR image, which was acquired at 2113 UTC 17 August 1995 (orbit: 21 388, frames: 747/ 765). On this image, sea surface manifestations of three internal wave trains propagating southward and one propagating northward can be identified. Regarding the available ERS 1/2 SAR dataset of the Strait of Messina, one has to note that, due to the different orbits flown by the ERS 1/2 satellites, more SAR images were acquired over 


\section{Overflights}

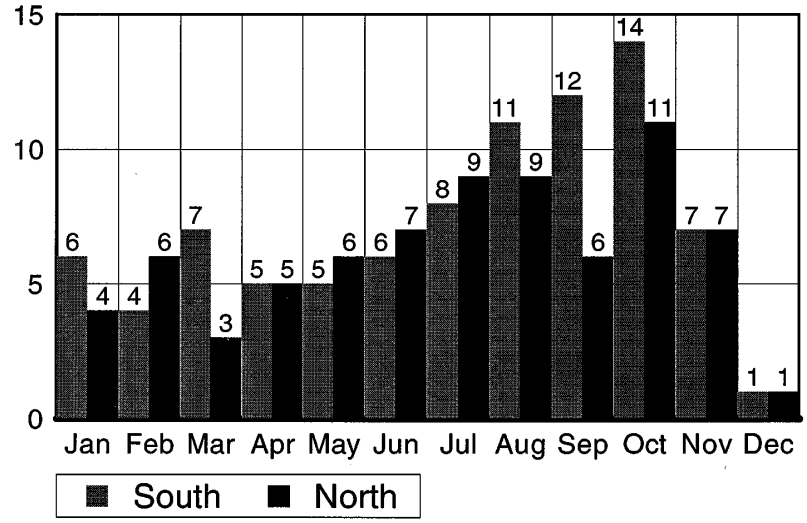

FIG. 2. Number of ERS 1/2 overflights per month over the Strait of Messina and adjacent sea areas between 1 December 1991 and 31 December 1995. Gray bars denote overflights during which SAR images over the region south of the sill were acquired, black bars denote overflights during which SAR images over the region north of the sill were acquired.

the Strait of Messina in the period from April to November than in the period from December to March (see Fig. 2).

The analysis of the available ERS 1/2 SAR images shows that sea surface manifestations of internal waves are observed more frequently during periods where a strong seasonal thermocline is known to be present, that is, during summer. Furthermore, sea surface manifestations of southward propagating internal waves can be delineated on ERS 1/2 SAR images more frequently than those of northward propagating ones (Fig. 3). In general, sea surface manifestations of southward propagating internal waves are stronger than those of northward propagating ones. The SAR image depicted in Fig. 1 shows evidence of such a north-south asymmetry in the sea surface manifestations of the internal wave field.

Figure 4 shows a time versus distance diagram delineating the propagation of internal bores north and south of the sill as inferred from the analyzed ERS 1/2 SAR images. In this figure, the distance between the fronts of internal wave trains and the sill, referenced to the time of maximum northward tidal flow at Punta Pezzo, is depicted. This distance is measured along a mean path of the center of the wave fronts, which is inferred from the available ERS $1 / 2$ SAR images. The lines are least square fits that yield for the northward propagating waves an average propagation speed of 1.00 $\mathrm{m} \mathrm{s}^{-1}$ and for the southward propagating waves an average propagation speed of $0.91 \mathrm{~m} \mathrm{~s}^{-1}$. From this figure, the time of release of internal bores from the sill can be estimated: Southward propagating internal bores are released from the sill between 1 and 5 hours after maximum northward tidal flow at Punta Pezzo, northward propagating internal bores between 2 and 6 hours after maximum southward tidal flow at Punta Pezzo, that is, between 8 and 12 hours after maximum northward tidal flow at Punta Pezzo. Figure 5 shows the spatial sepa-
Internal Wave Observations

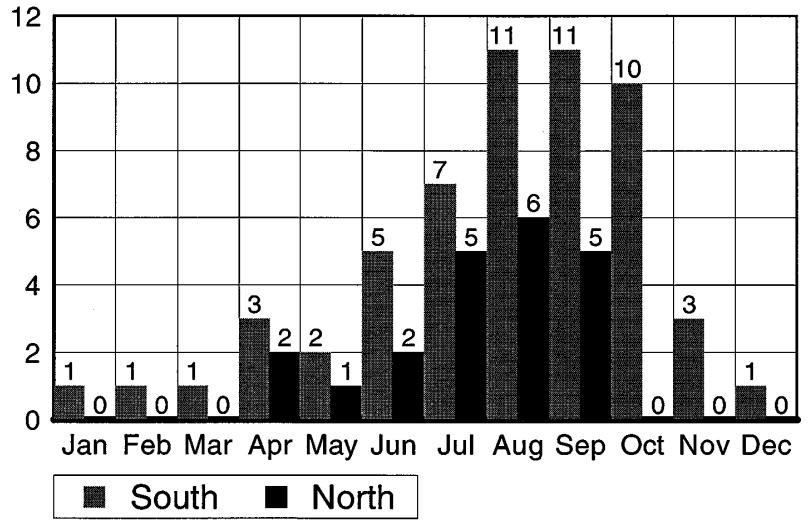

FIG. 3. Number of internal wave observations per month made on the ERS 1/2 SAR images listed in Fig. 2. Gray bars denote internal wave observations south of the sill, black bars internal wave observations north of the sill.

ration between the first two internal solitary waves of northward and southward propagating wave trains as a function of the distance from sill as inferred from $E R S$ $1 / 2$ SAR images. This spatial separation ranges from $500 \mathrm{~m}$ to $1900 \mathrm{~m}$ for southward propagating wave trains, and from $350 \mathrm{~m}$ to $1000 \mathrm{~m}$ for northward propagating wave trains in the region considered here. Figure 5 shows that, in general, the spatial separation between the first two internal solitary waves of southward propagating wave trains is smaller in the period from July to September than in the period from October to June.

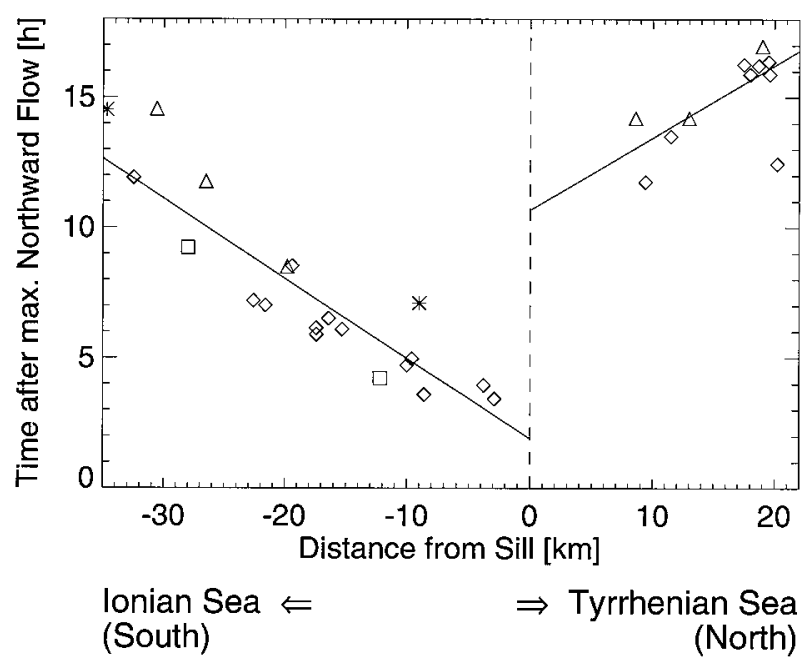

FIG. 4. Space-time diagram showing the propagation of the front of northward and southward propagating internal wave trains in the Strait of Messina as inferred from ERS 1/2 SAR images. Diamonds refer to observations made between July and September, triangles to observations made between April and June, squares to observations made between October and December, and stars to observations made between January and March. The lines are least square fits that yield for the front of northward and southward propagating internal waves trains the propagation speeds $1.00 \mathrm{~m} \mathrm{~s}^{-1}$ and $0.91 \mathrm{~m} \mathrm{~s}^{-1}$, respectively. 


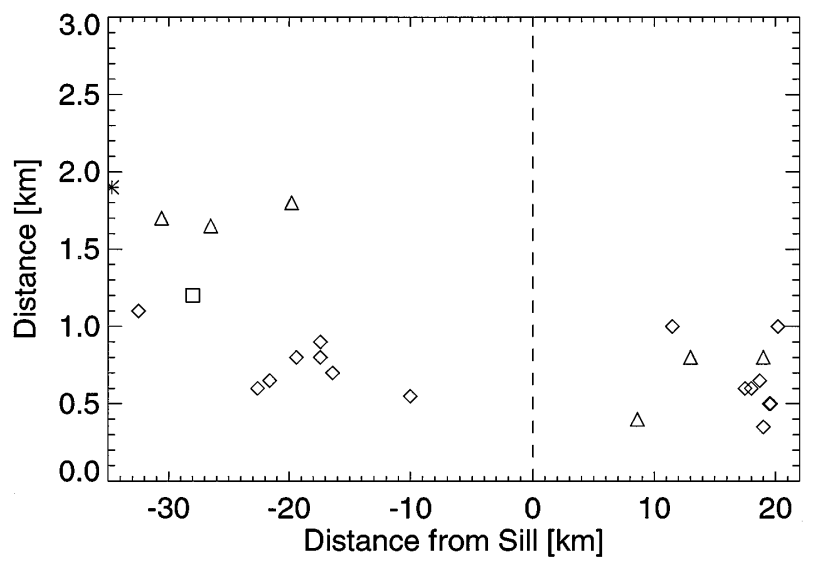

$\underset{\text { lonian Sea }}{\text { (South) }} \quad \Rightarrow \underset{\text { (North) }}{\text { Tyrrhenian Sea }}$

FIG. 5. Spatial separation between the first two internal solitary waves of northward and southward propagating wave trains as a function of distance from sill as inferred from ERS 1/2 SAR images. Diamonds refer to observations made between July and September, triangles to observations made between April and June, the square refers to an observation made between October and December, and the star to an observation made between January and March.

A detailed comparison of the spatial separation between the first two internal solitary waves as inferred from ERS $1 / 2$ SAR images and as calculated with our numerical model will be presented in section 7 .

Figures 6 and 7 show two ERS 1 SAR images acquired at 0941 UTC 11 July 1993 (orbit: 10 387, frame: 2835) and at 2114 UTC 13 July 1995 (orbit: 20 887, frame: 765). On both images sea surface manifestations of northward propagating internal solitary waves are visible. Note the pronounced difference in shape, wavelength, and modulation depth of the sea surface manifestations of these two wave trains. The wave train visible on the image depicted in Fig. 6 has a strong surface signature and a weak wave front curvature. It propagates along the Calabrian coast in the direction of the strait axis. On the contrary, the wave train visible on the image depicted in Fig. 7 has a weak surface signature, a strong wave front curvature, and it propagates almost spherically from the northern mouth of the Strait of Messina into the Tyrrhenian Sea. The large variability in the sea surface manifestations of northward propagating internal waves is a general feature that we have noticed in the analysis of the ERS 1/2 SAR images.

\section{The model}

\section{a. Theory}

The proposed model for the description of the water mass dynamics in the Strait of Messina is a two-layer model as schematically depicted in Fig. 8. In this figure, $D$ is the water depth, $h_{1}$ and $h_{2}$ are the thicknesses of the upper and lower layers respectively, $\zeta_{1}$ is the sea surface displacement, and $\zeta_{2}$ is the distance of the in-

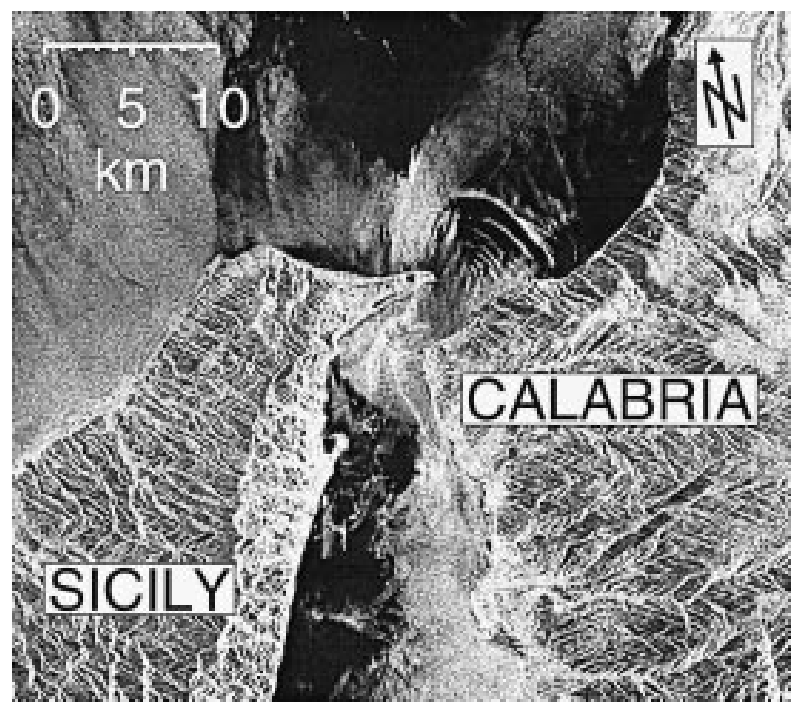

FIG. 6. ERS 1 SAR image of the Strait of Messina acquired at 0941 UTC 11 July 1993, 20 min after maximum northward tidal flow at Punta Pezzo. The image shows strong sea surface manifestations of an internal wave train propagating northward into the Tyrrhenian Sea.

terface from the mean sea surface. The model is capable of describing the flow of a two-layer water mass through a channel with a variable water depth and a variable width. The governing equations used in this investigation are the nonlinear primitive Boussinesq equations for two water layers. They are obtained from a perturbation expansion of the Laplace equation for the velocity potential for both layers in the case of shallow water and small wave amplitude. In terms of the expansion parameters $\mu^{2}$ and $\epsilon$, defined by $\mu^{2}=k^{2} H^{2}$ and

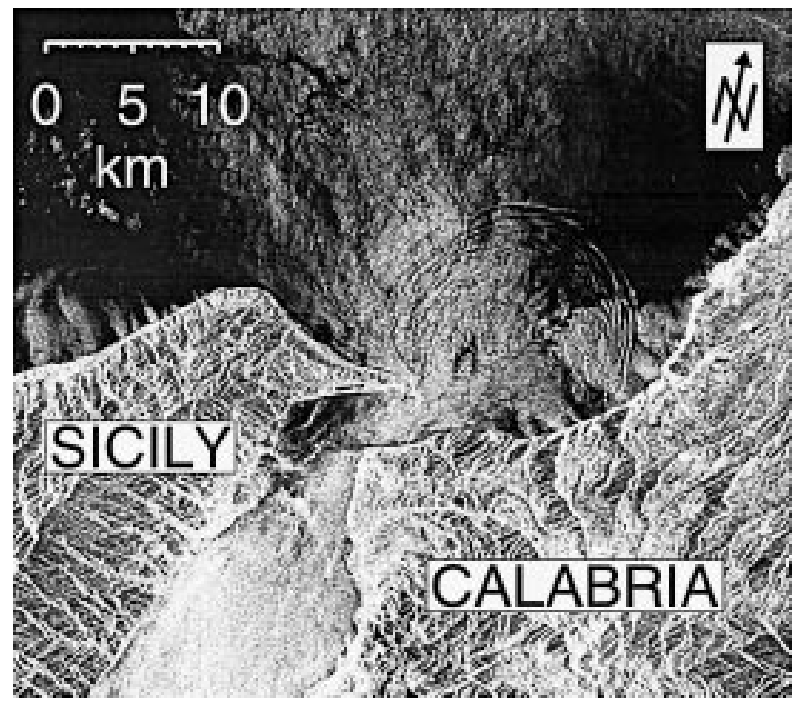

FIG. 7. ERS 1 SAR image of the Strait of Messina acquired at 2114 UTC 13 July 1995, 3 h 57 min after maximum northward tidal flow at Punta Pezzo. The image shows weak sea surface manifestations of an internal wave train propagating northward into the Tyrrhenian Sea. 


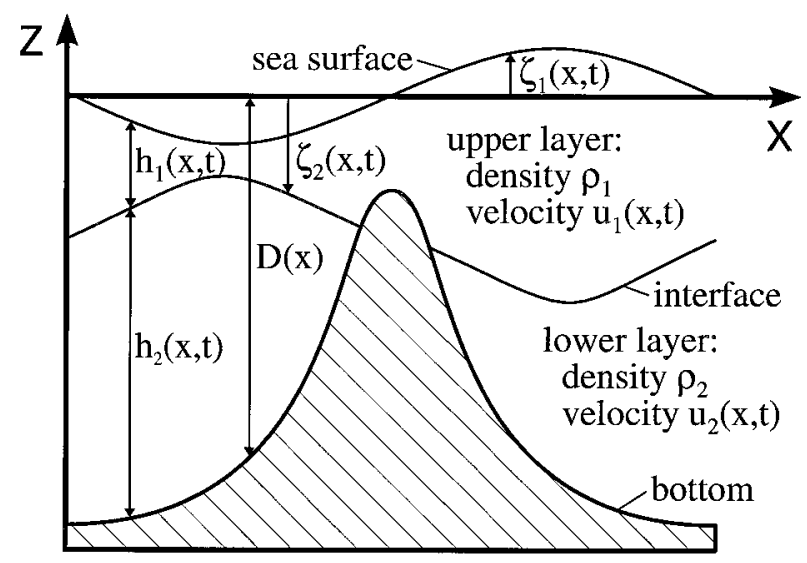

FIG. 8. Schematic plot of the two-layer system. Here $D$ denotes the mean water depth, $h_{1}$ and $h_{2}$ the thicknesses of the upper and lower layer respectively, $\zeta_{1}$ the sea surface displacement, and $\zeta_{2}$ the distance of the interface from the mean sea surface. $\epsilon=a H^{-1}$, where $a$ and $k$ denote the amplitude and the wavenumber of the internal wave respectively, and $H$ denotes a characteristic depth scale; the model is valid for $\epsilon \ll 1$ and $\mu^{2} \ll 1$. In the Boussinesq equations only terms $O\left(\mu^{2}, \epsilon\right)$ are retained and terms $O\left(\mu^{4}, \mu^{2} \epsilon\right.$, ...) are neglected. The hydrostatic shallow-water equations, which are used in the generation model, are obtained by neglecting also terms $O\left(\mu^{2}\right)$. Furthermore, the model requires that the water depth $D=D(x)$ and the channel width $W=W(x)$ are weakly varying functions of the space variable $x$. In this model we assume that the channel has a rectangular cross section. The equations used in our model include horizontal momentum diffusion and vertical shear stress terms at the bottom and at the interface between the two water layers. In the following we denote the vertically and horizontally (perpendicular to the strait axis) averaged velocities and transports by $u_{i}$ and $Q_{i}=u_{i} h_{i} W$ respectively. The subscripts $i=1$ and $i=2$ refer to the upper and lower layer respectively. For the upper layer, the momentum and the continuity equations read

$$
\begin{aligned}
\frac{\partial Q_{1}}{\partial t}+\frac{\partial}{\partial x}\left(u_{1} Q_{1}\right)+g h_{1} W \frac{\partial \zeta_{1}}{\partial x}-A_{H} h_{1} W \frac{\partial^{2} u_{1}}{\partial x^{2}}+W \frac{\tau_{\text {int }}}{\bar{\rho}}-\frac{h_{1}^{2}}{6} \frac{\partial^{3} Q_{2}}{\partial x^{2} \partial t}=0 \\
\frac{\partial \zeta_{1}}{\partial t}+\frac{1}{W}\left(\frac{\partial Q_{1}}{\partial x}+\frac{\partial Q_{2}}{\partial x}\right)=0
\end{aligned}
$$

while for the lower layer the corresponding equations read

$$
\begin{array}{r}
\frac{\partial Q_{2}}{\partial t}+\frac{\partial}{\partial x}\left(u_{2} Q_{2}\right)+g h_{2} W \frac{\partial \zeta_{1}}{\partial x}+g^{\prime} h_{2} W \frac{\partial \zeta_{2}}{\partial x}-A_{H} h_{2} W \frac{\partial^{2} u_{2}}{\partial x^{2}}-W \frac{\tau_{\text {int }}-\tau_{\text {bot }}}{\bar{\rho}}-\left(\frac{h_{2}^{2}}{3}+\frac{h_{2} h_{1}}{2}\right) \frac{\partial^{3} Q_{2}}{\partial x^{2} \partial t}=0 \\
\frac{\partial \zeta_{2}}{\partial t}+\frac{1}{W} \frac{\partial Q_{2}}{\partial x}=0 .
\end{array}
$$

Here $g^{\prime}=g \Delta \rho / \bar{\rho}$ denotes the reduced gravity, $g$ is the acceleration of gravity, $\Delta \rho=\rho_{2}-\rho_{1}$ is the density difference between the two layers, $\bar{\rho}=\left(\rho_{1}+\rho_{2}\right) / 2$ is the mean water density, $A_{H}$ is the horizontal eddy viscosity coefficient, $\tau_{\text {int }}$ is the vertical shear stress at the interface, and $\tau_{\text {bot }}$ is the bottom stress. The stresses $\tau_{\text {int }}$ and $\tau_{\text {bot }}$ are assumed to depend on the current velocities in the upper and lower layers, $u_{1}$ and $u_{2}$, respectively, in the following way:

$$
\begin{aligned}
& \frac{\tau_{\text {int }}}{\bar{\rho}}=r_{\text {int }}\left|u_{1}-u_{2}\right|\left(u_{1}-u_{2}\right) \\
& \frac{\tau_{\text {bot }}}{\bar{\rho}}=r_{\text {bot }}\left|u_{2}\right| u_{2} .
\end{aligned}
$$

Here $r_{\text {int }}$ and $r_{\text {bot }}$ denote the nondimensional friction parameters at the interface and the bottom respectively. The last terms in the two momentum equations (2) and (4) describe the weakly nonhydrostatic effects in the Boussinesq equations. Note that in our model we have neglected the Coriolis force. In order to minimize reflections at the open boundaries, we have implemented in our model the Orlanski radiation condition (Orlanski 1976).

We have introduced in (2) and (4) horizontal diffusion terms in order to avoid the development of flow discontinuities at the transitions between subcritical and supercritical flow (e.g., see Woodward and Colella 1984; Oğuz et al. 1990). In our model we assume that the 
horizontal eddy viscosity coefficient $A_{H}$ is constant and have chosen the value of $A_{H}$ as the minimum value ensuring numerical stability.

\section{b. The generation and propagation models}

The numerical model presented in this paper is a composite of two models consisting of 1) a hydrostatic "generation model" equipped with movable lateral boundaries and 2) a weakly nonhydrostatic "propagation model." The first model describes the dynamics of the water masses in the region close to the strait's sill where the internal bores are generated (generation region), and the second model describes the dynamics of the water masses outside of this region where the internal bores may disintegrate into internal solitary waves (propagation region).

In the generation model, the weakly nonhydrostatic terms that appear in the momentum equations (2) and (4) are neglected. In this model, we allow the lower layer to intersect the bottom topography, which is achieved by introducing movable lateral boundaries for the lower layer. For those grid points where no lower layer exists, we treat the integration domain as composed of only one active upper layer. For further details about the treatment of movable lateral boundaries, the reader is referred to the papers of Backhaus (1976) and Jungclaus and Backhaus (1994). In order to maintain numerical stability, the interface depth has been lowpass filtered every 100 time steps in the sill region. The equations are discretized on a staggered Arakawa C-grid and the time-stepping procedure is performed by an explicit two-time-level scheme.

In the propagation model the complete set of equations (2)-(5), which include also the weakly nonhydrostatic terms, are solved. As in the generation model the equations are discretized on a staggered Arakawa $\mathrm{C}$-grid. However, here the time-stepping procedure is performed by an implicit two-time-level scheme.

Due to the explicit scheme used in the generation model, the calculation is staggered in time. This means that, for every model iteration, the calculated displacement values $\zeta_{i}$ and the calculated transport values $Q_{i}$ are determined for the times $t-\Delta t / 2$ and $t$ respectively, where $\Delta t$ is the time step used in the calculations. On the other hand, in the implicit scheme used in the propagation model both the displacement values $\zeta_{i}$ and the transport values $Q_{i}$ are determined for the same time $t$. The two-way coupling between the generation and propagation model for each iteration is implemented as follows: If $\zeta_{i}(t-\Delta t / 2)$ and $Q_{i}(t)$ are known for the whole integration domain, the explicit generation model yields $\zeta_{i}(t+\Delta t / 2)$ for the whole integration domain and $Q_{i}(t$ $+\Delta t)$ for the generation region. The values $Q_{i}(t+\Delta t)$ for the generation region are inserted as boundary conditions into the propagation model. Averaging $\zeta_{i}(t-$ $\Delta t / 2)$ and $\zeta_{i}(t+\Delta t / 2)$ yields $\zeta_{i}(t)$. Using $\zeta_{i}(t), Q_{i}(t)$, and the boundary conditions $Q_{i}(t+\Delta t)$, the implicit prop-

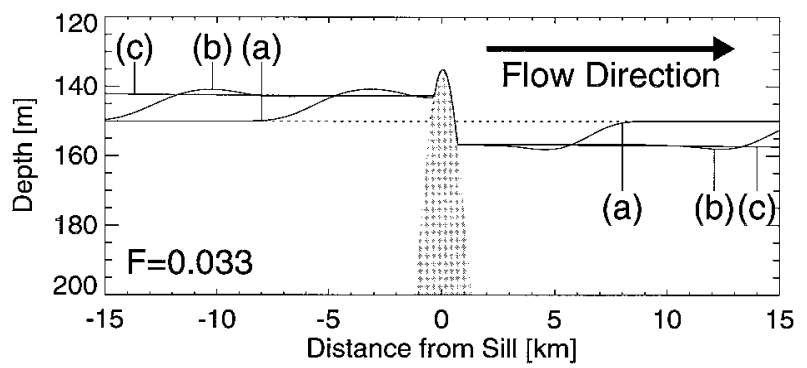

FIG. 9. Space-time evolution of the interface between two water layers for a Froude number $F=0.033$. The form of the interface is shown for three selected times: (a) $t=2 \mathrm{~h} 30 \mathrm{~min}$, (b) $t=5 \mathrm{~h}$, and (c) $t=10 \mathrm{~h}$. For this Froude number, the lower layer flow is totally blocked by the sill. The dotted line represents the depth of the undisturbed interface at $t=0$. The profile of the sill is the same as in Figs. 10, 11, and 12. Note that in this plot the depth scale is from 120 to $200 \mathrm{~m}$.

agation model yields the transport values $Q_{i}(t+\Delta t)$ in the propagation regions. This procedure is repeated step by step in time. The exact location of the two boundaries between the generation region and the propagation regions will be specified in section 6 a.

\section{Model test}

\section{a. Test of the generation model}

In order to test the generation model, we have carried out numerical simulations for the same flow types as investigated by Baines (1984). He performed laboratory experiments for studying the stationary flow of a twolayer fluid over topography for different values of the internal Froude numbers $F$. The Froude number is defined as $F=U /\left(g^{\prime} H_{2}\right)^{1 / 2}$, where $U$ denotes the velocity of the undisturbed flow, which here is assumed to be the same in both layers, and $H_{1}$ and $H_{2}$ denote the undisturbed thicknesses of the upper and lower layer respectively. The channel width is assumed to be constant and the sill to have the following depth profile

$$
D=D_{\max }-\left(D_{\max }-D_{\min }\right) \cosh ^{-2}\left(\frac{x}{L}\right),
$$

where $D_{\max }$ the maximum water depth, $D_{\min }$ the minimum water depth (at the sill), and $L$ the horizontal length scale of the sill. The center of the sill is located at $x=$ 0 . In our simulations we have chosen: $H_{1}=150 \mathrm{~m}, H_{2}$ $=150 \mathrm{~m}, D_{\max }=300 \mathrm{~m}, D_{\min }=135 \mathrm{~m}, L=1667 \mathrm{~m}$, and $g^{\prime}=9.5 \times 10^{-3} \mathrm{~m} \mathrm{~s}^{-2}$.

Three cases with different Froude numbers are studied: (a) $F=0.033$, (b) $F=0.51$, and (c) $F=1.25$, which are shown in Figs. 9, 10, and 11 respectively. Case a $(F=0.033$, subcritical $)$ describes a flow type where the lower layer flow is totally blocked by the sill (Fig. 9). Case b ( $F=0.51$, near critical) describes a flow type where an internal hydraulic jump is formed downstream of the sill (Fig. 10). For both cases, a new, larger upstream lower layer thickness will be achieved, 


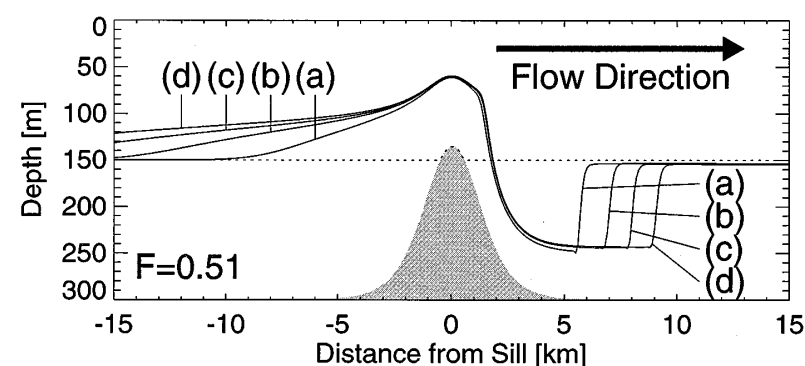

FIG. 10. As in Fig. 9 but for Froude number $F=0.51$. The form of the interface is shown for four selected times: (a) $t=6 \mathrm{~h}$, (b) $t$ $=12 \mathrm{~h}$, (c) $t=18 \mathrm{~h}$, and (d) $t=24 \mathrm{~h}$. For this Froude number, corresponding to near-critical flow, an internal hydraulic lee jump develops.

which represents the adjustment of the system to the condition of critical flow immediately upstream of the sill (Baines 1984). Case c $(F=1.25$, supercritical) describes a flow type that is everywhere supercritical. After a transient phase, a stationary symmetrical bump is formed over the sill and no upstream disturbances are generated (see Fig. 11). Figure 12 shows the first halfhour of the evolution of the interface for case $b$. This figure illustrate the "run-up" of the lower layer on the upstream side of the sill. Note that, while bottom and interface friction have been neglected in these simulations, only in the last two simulations has an eddy viscosity been introduced in order to maintain numerical stability. The simulated flow types agree at least qualitatively with the flow types found experimentally by Baines (1984). Due to the periodic tidal flow in the Strait of Messina, these different flow types can occur in the sill region. We feel confident, therefore, that our model is capable of describing correctly the interaction of a tidal flow with a sill where the lower layer may intersect the bottom topography.

\section{b. Test of the propagation model}

It is well known that, from internal disturbances propagating in a weakly nonhydrostatic, nonlinear medium as described by the Boussinesq equations (2)-(5), in the case of constant depth and width, waves of constant shape may evolve, which are called internal solitary waves (Keulegan 1953; Long 1956; Benjamin 1966; Benny 1966; Miles 1979). Different equations, with different degrees of accuracy, have been derived for describing the propagation of internal solitary waves. In this section we compare our numerical solutions of the Boussinesq equations (2)-(5) for solitary waves with the analytical solutions of the Korteweg-de Vries (KdV) equation (Korteweg and de Vries 1895; Djordjevic and Redekopp 1978), the extended KdV equation (Koop and Butler 1981), the Benjamin-Ono equation (Benjamin 1967; Ono 1975), and the Miyata equations (Miyata 1988). In this comparison we assume, for simplicity, that the water depth and the channel width are constant

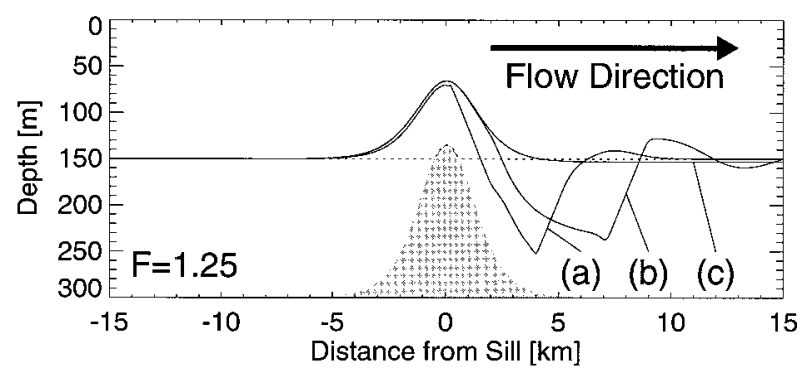

FIG. 11. As in Fig. 9 but for Froude number $F=1.25$. The form of the interface is shown for three selected times: (a) $t=1 \mathrm{~h}$, (b) $t$ $=2 \mathrm{~h}$, and (c) $t=12 \mathrm{~h}$. For this Froude number, corresponding to supercritical flow, a symmetric, stationary bump establishes over the sill at $t=12 \mathrm{~h}$.

and that there is no diffusion and no friction. In the simulations carried out for this comparison we have chosen the following values for the parameters: $g^{\prime}=$ $20 \times 10^{-3} \mathrm{~m} \mathrm{~s}^{-2}, H_{1}=150 \mathrm{~m}$, and $H_{2}=850 \mathrm{~m}$. Solitary wave solutions of the $\mathrm{KdV}$ equation with different amplitudes have been used as initial conditions for our numerical simulations. As the numerical model has produced waves of constant shape, such shape, together with the corresponding phase speed, has been used for the comparison of our numerical solutions with the different analytical solutions.

Among the aforementioned equations, only the Miyata equations can describe internal wave forms whose amplitudes are of the same order as the characteristic water depth $H=H_{1} H_{2} /\left(H_{1}+H_{2}\right)$ (Miyata 1988). For the case of constant water depth, Miyata (1988) found an analytical solitary wave solution of these equations.

Figure 13 depicts the wavelength-amplitude relationship in nondimensional form calculated with the various models. Here the wavelength $L$ of a solitary wave (equivalent-square-wavelength) is defined by

$$
L=\frac{1}{2 A} \int_{-\infty}^{\infty}\left(H_{1}-\zeta_{2}\right) d x,
$$

where $A$ denotes the amplitude (peak to trough) of the

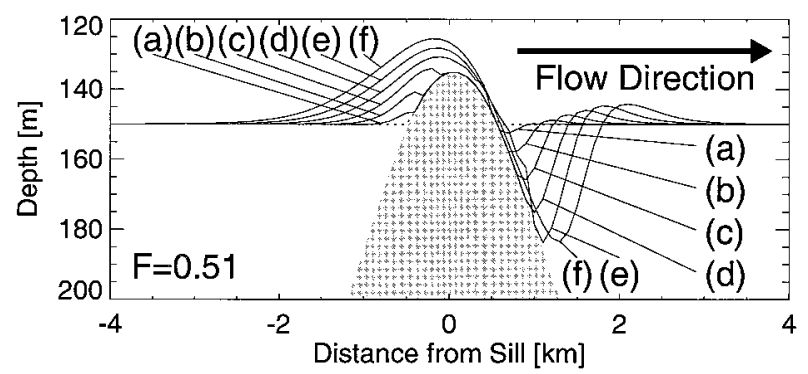

FIG. 12. As in Fig. 10 but for smaller times. The form of the interface is shown for the times: (a) $t=5 \mathrm{~min}$, (b) $t=10 \mathrm{~min}$, (c) $t=15 \mathrm{~min}$, (d) $t=20 \mathrm{~min}$, (e) $t=25 \mathrm{~min}$, and (f) $t=30 \mathrm{~min}$. This figure shows the lower layer "run-up" on the upstream side of the sill for a near-critical flow. Note that in this plot the depth scale is from 120 to $200 \mathrm{~m}$ and the length scale from -4 to $+4 \mathrm{~km}$. The profile of the sill is the same as in Figs. 9, 10, and 11. 


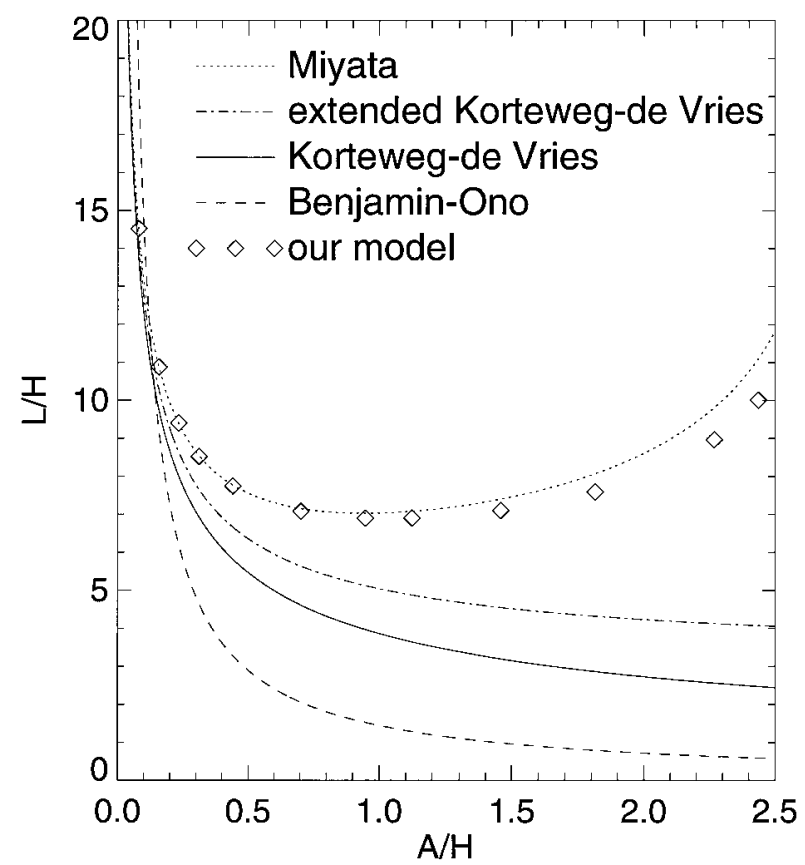

FIG. 13. Relationship between nondimensional wavelength, $L / H$, and nondimensional amplitude, $A / H$, of internal solitary waves as given by different (soliton) models.

solitary wave. Figure 13 shows that the solitary wave solutions of our propagation model agree quite well with the solutions of the Miyata equations. The wavelength of solitary waves calculated with the Miyata equations

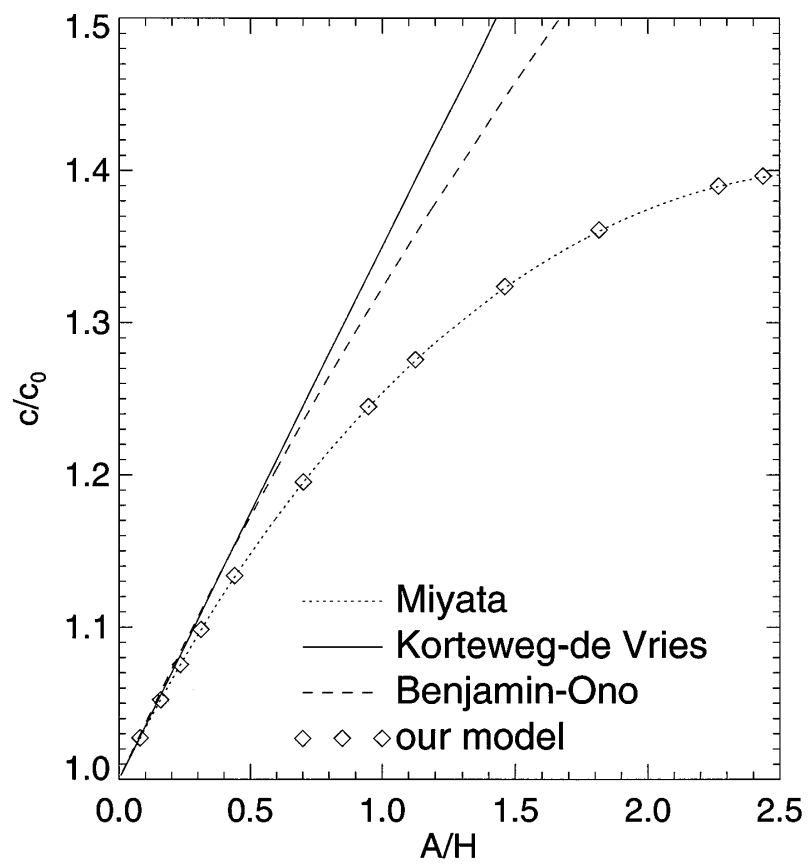

FIG. 14. Relationship between nondimensional phase speed, $c / c_{0}$, and nondimensional amplitude $A / H$ of internal solitary waves as given by different (soliton) models.
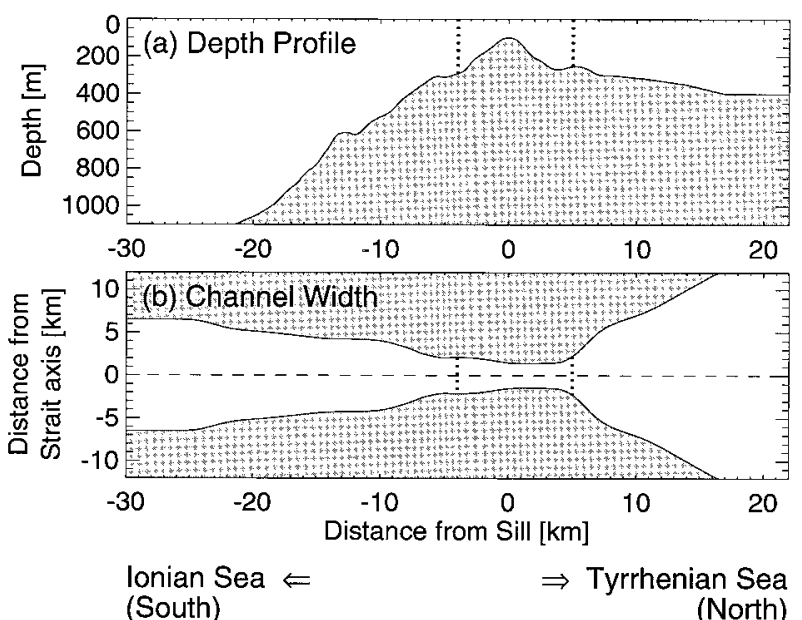

FIG. 15. Topography of the Strait of Messina used in the simulations. The depth profile is depicted in (a) and the channel width in (b). The dotted vertical lines in (a) and (b) separate the model domain in a generation region around the sill and in two propagation regions north and south of this generation region.

as well as from our model increases with increasing amplitude for large amplitude waves $(A / H \gtrsim 1)$. This is a consequence of the fact that, as the wave amplitude increases, the nonlinear effects due to the motion in the lower layer increase and tend to compensate the nonlinear effects due to the motion in the upper layer. Since nonlinear effects are responsible for the wave steepening, the attenuation of the coupled nonlinear effect due to the motion in both layers must lead to an increase of the wavelength. Figure 14 depicts the phase speedamplitude relationship in nondimensional form calculated with the various models. Although the Boussinesq model is derived by assuming that the amplitude of the wave is small, we see that the wavelength-amplitude and the phase speed-amplitude relationships calculated numerically with our propagation model agree quite well with the relationships calculated analytically with the Miyata equations (see Figs. 13, 14). Therefore, we feel confident that our propagation model is also capable of describing correctly the propagation of internal solitary waves in the Strait of Messina, where the internal solitary waves have amplitudes that often are not small compared to the characteristic water depth.

\section{Simulations of internal waves in the Strait of Messina}

\section{a. Model parameters}

In the model calculations presented in this section we approximate the bottom topography of the Strait of Messina by the depth profile and the channel width, which are plotted in Figs. 15a and 15b. The model domain covers a distance of $70 \mathrm{~km}$ in the alongchannel direction. However, in the plots only a range of $52 \mathrm{~km}$ around the sill is shown. All quantities are plotted as a function of 
TABLE 1. Values of parameters used in the numerical simulations.

\begin{tabular}{lc}
\hline \hline Grid spacing, $\Delta x(\mathrm{~m})$ & 100 \\
Time step, $\Delta t(\mathrm{~s})$ & 1 \\
Horizontal eddy viscosity coefficient, $A_{H}\left(\mathrm{~m}^{2} \mathrm{~s}^{-1}\right)$ & 10 \\
Interfacial friction parameter, $r_{\text {int }}$ & 0.001 \\
Bottom friction parameter, $r_{\text {bot }}$ & 0.01 \\
\hline
\end{tabular}

the alongchannel coordinate $x$. At the sill $(x=0)$ the water depth is $98 \mathrm{~m}$. The strait is narrowest at a location $1.5 \mathrm{~km}$ north of the sill where the channel width is 2.8 $\mathrm{km}$ (see Fig. 15). The boundaries between the generation region in the sill area and the propagation regions north and south of the sill area are chosen such that their locations has no significant influence on the evolution of northward and southward propagating internal waves. After several test runs we set the boundary north of the sill region at $x_{n}=5 \mathrm{~km}$ and the boundary south of the sill region at $x_{s}=-4 \mathrm{~km}$. For $x_{s} \leq x \leq x_{n}$, the generation model is used, outside of this region the propagation model is used. The two-layer system is forced by imposing barotropic, semidiurnal tidal displacements at the two open boundaries. The imposed tide has been chosen in accordance with Vercelli's data (Vercelli 1925): The amplitudes at the northern and southern boundary are 17 and $10 \mathrm{~cm}$ respectively, the phase difference is $174^{\circ}$ and the semidiurnal tidal period is $12.4 \mathrm{~h}$. The other model parameters used in the simulations are given in Table 1.

In order to explain the peculiarities of the observed internal wave field in the Strait of Messina, two different numerical simulations with different parameters of the undisturbed interface depth $H_{1}$ and of the reduced gravity $g^{\prime}$ are presented in this section. The first numerical simulation refers to a scenario in which a strong seasonal thermocline is present in the Strait of Messina. The interface depth is $30 \mathrm{~m}$ and the reduced gravity is 14.7 $\times 10^{-3} \mathrm{~m} \mathrm{~s}^{-2}$ (Table 2, thermocline). The second numerical simulation refers to a scenario in which no seasonal thermocline is present in the Strait of Messina; here the interface between the two water masses, the TSW and LIW, which exist throughout the year in the area, is present. The interface depth is $150 \mathrm{~m}$ and the reduced gravity is $4.9 \times 10^{-3} \mathrm{~m} \mathrm{~s}^{-2}$ (Table 2 , no thermocline). The simulations have been carried out by running the model for several tidal cycles until an almost periodic solution developed.

\section{b. Simulation with a seasonal thermocline}

In the simulation presented in this section we assume that the stratification of the water body in the Strait of Messina is due to a seasonal thermocline located at a depth of $30 \mathrm{~m}$. The reduced gravity associated with this seasonal thermocline is assumed to be $14.7 \times 10^{-3} \mathrm{~m}$ $\mathrm{s}^{-2}$. Our simulation yields the result that in the sill region the amplitudes of the total tidal transport, the tidal transport in the upper layer, and the tidal transport in the
TABLE 2. Values of parameters, characterizing the water stratification, used in the numerical simulations with thermocline and with no thermocline.

\begin{tabular}{lcc}
\hline \hline & Thermocline & $\begin{array}{c}\text { No } \\
\text { thermocline }\end{array}$ \\
\hline $\begin{array}{l}\text { Interface depth, } H_{1}(\mathrm{~m}) \\
\text { Reduced gravity, } g^{\prime}\left(\mathrm{ms}^{-2}\right)\end{array}$ & $14.7 \times 10^{-3}$ & $4.9 \times 10^{-3}$ \\
\hline
\end{tabular}

lower layer have the values $0.55,0.15$, and $0.4 \mathrm{~Sv}(1$ $\left.\mathrm{Sv} \equiv 1 \times 10^{6} \mathrm{~m}^{3} \mathrm{~s}^{-1}\right)$ respectively. The mean transports in the upper and lower layer are $0.02 \mathrm{~Sv}$ into the Ionian Sea and $0.06 \mathrm{~Sv}$ into the Tyrrhenian Sea, respectively.

Figure 16 shows the interface depth for six different times separated by $1 / 6$ of the tidal cycle with period $T$. In the bottom panels of Fig. 16 the depth profile used in the simulations is depicted. The arrows indicate the
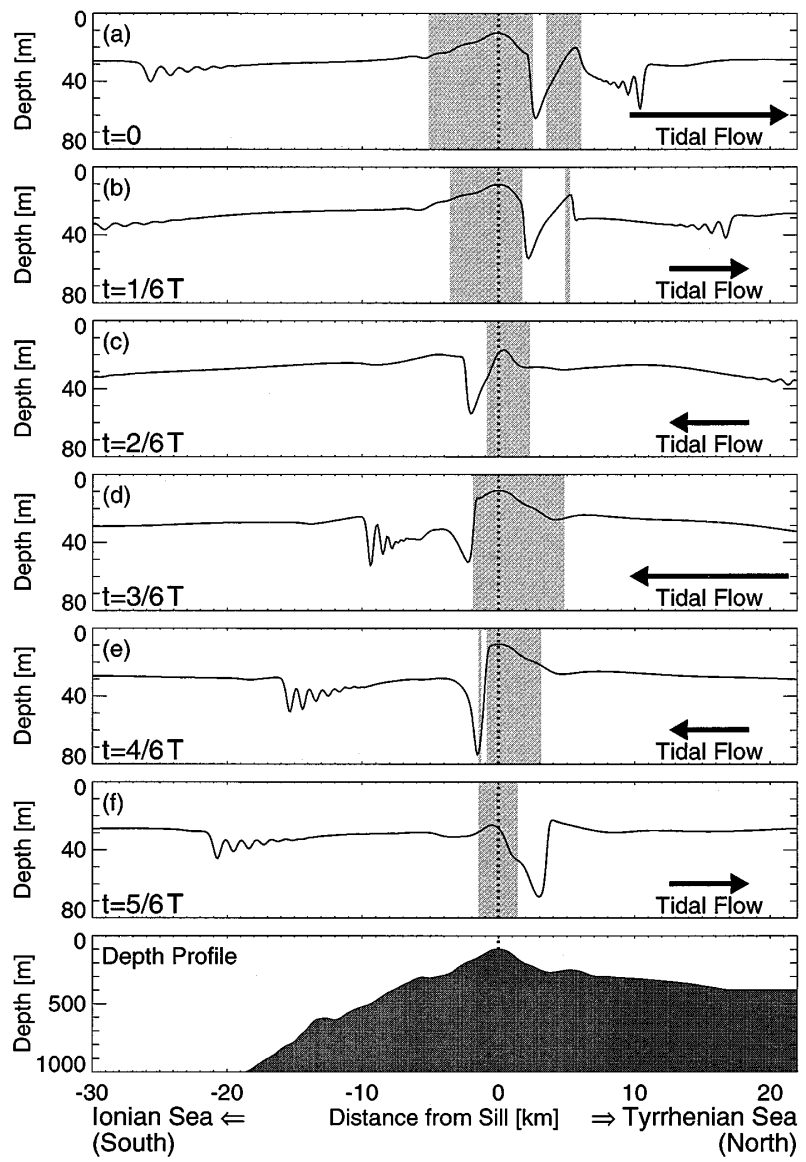

FIG. 16. Space-time evolution of the interface between the two water layers as calculated with the numerical model in the case of a seasonal thermocline. The undisturbed interface depth is $30 \mathrm{~m}$ and the reduced gravity is $14.7 \times 10^{-3} \mathrm{~m} \mathrm{~s}^{-2}$. The form of the interface is shown at different phases of the tidal cycle as a function of distance from the sill $(x=0)$. The time $t=0$ corresponds to maximum northward tidal flow. The light gray shaded areas mark the regions where the flow is supercritical. These plots illustrate how the form of the interface varies during one tidal cycle ( $T$ is the tidal period) and how a train of internal solitary waves evolves. 

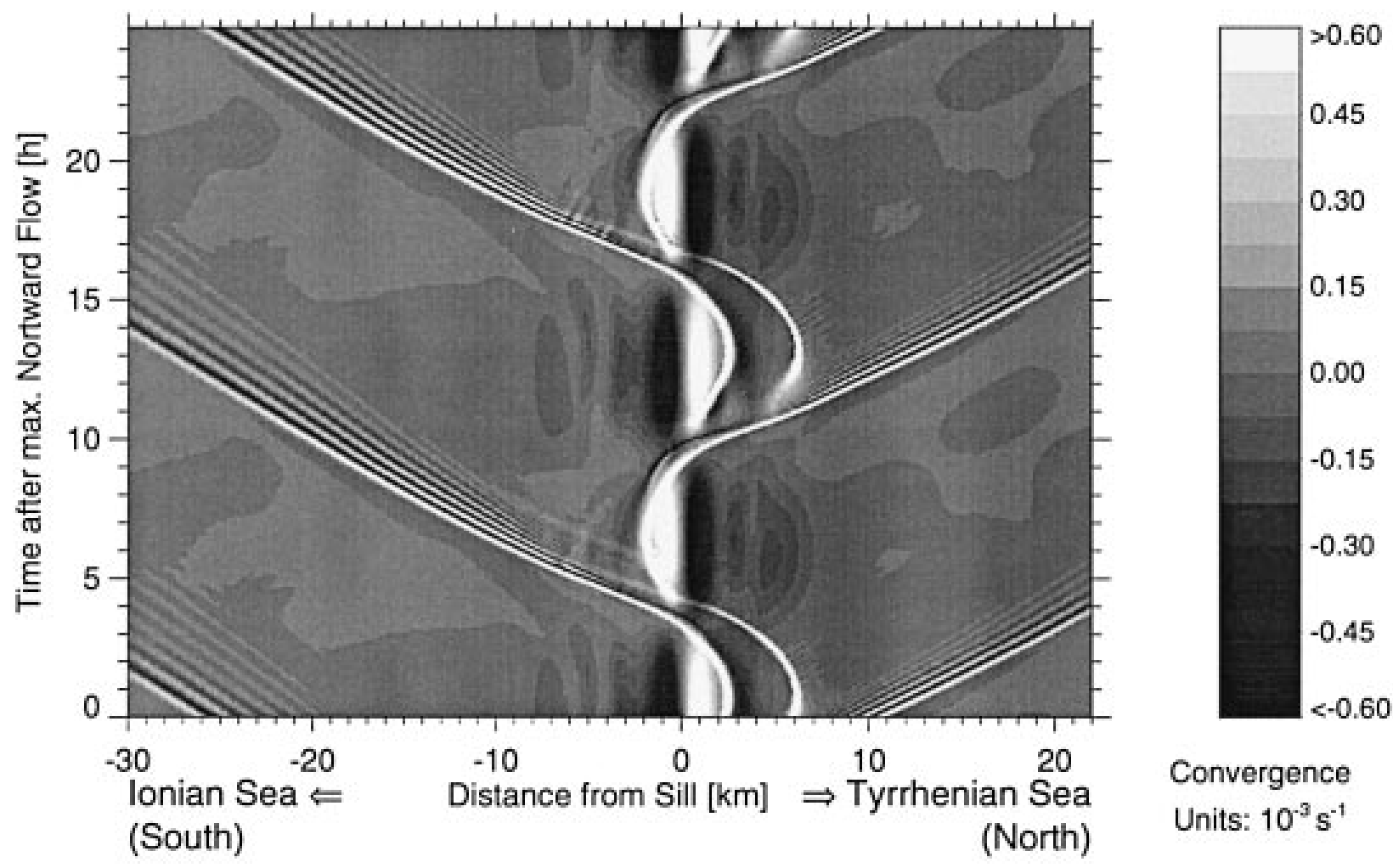

Convergence

Units: $10^{-3} \mathrm{~s}^{-1}$

FIG. 17. Space-time diagram showing the evolution of the surface convergence associated with internal waves as calculated with the model in the case of a seasonal thermocline. The undisturbed interface depth is $30 \mathrm{~m}$ and the reduced gravity is $14.7 \times 10^{-3} \mathrm{~m} \mathrm{~s}^{-2}$. The gray levels indicate the strength of the surface convergence as a function of distance from the sill $(x=0)$ and time after maximum northward flow $(t$ $=0$ ). Note that the surface convergence is, to first order, proportional to the variation of the relative radar cross section.

direction and the strength of the tidal flow at the sill. The light gray shaded areas mark the regions where the composite Froude number $G$, defined by

$$
G^{2}=\frac{u_{1}^{2}}{g^{\prime} h_{1}}+\frac{u_{2}^{2}}{g^{\prime} h_{2}},
$$

is larger than 1. In these regions the flow is supercritical and it is connected to the subcritical flow on the downstream side by an internal hydraulic jump.

At maximum northward tidal flow, the interface at the sill is lifted upward while, north of the sill, a strong interfacial depression is present (Fig. 16a). At slack water the depression (internal bore) starts propagating southward and approaches the sill. Due to amplitude dispersion its steepness increases (Fig. 16c). As a consequence, frequency dispersion is strengthened and the coupled effect of these two dispersions causes the bore to disintegrate, thus giving birth to a train of internal solitary waves (Figs. 16d and 16e). At maximum southward tidal flow, the interface at the sill is again lifted upward, while south of the sill a strong interfacial depression is present (Fig. 16d). As discussed for the evolution of the southward propagating internal bore, this depression passes the sill and disintegrates into a train of northward propagating internal solitary waves (Fig. 16a). Note that, close to the sill, the shapes of the north- ward and southward propagating internal solitary waves are very similar (compare Fig. 16a with 16d), whereas farther away their shapes are quite different (compare Fig. 16b with 16e). This north-south asymmetry of the wave field is mainly caused by the north-south asymmetry of the channel width. Northward propagating internal waves are attenuated more strongly than southward propagating ones because in the northern section the channel is wider.

Figure 17 shows the simulated surface convergence field in a space-time diagram for two tidal cycles. As discussed in section $3 \mathrm{~b}$, the surface convergence associated with internal waves is proportional to the measured relative variation of the NRCS. Our simulation with a seasonal thermocline yields the result that internal solitary wave trains are generated that propagate northward as well as southward. The persistent surface convergence patterns in the sill region are due to the strong interfacial depressions caused by the internal tide dynamics.

\section{c. Simulation with no seasonal thermocline}

In the simulation presented in this section we assume that the stratification of the water body in the Strait of Messina is solely due to the presence of the TSW and 

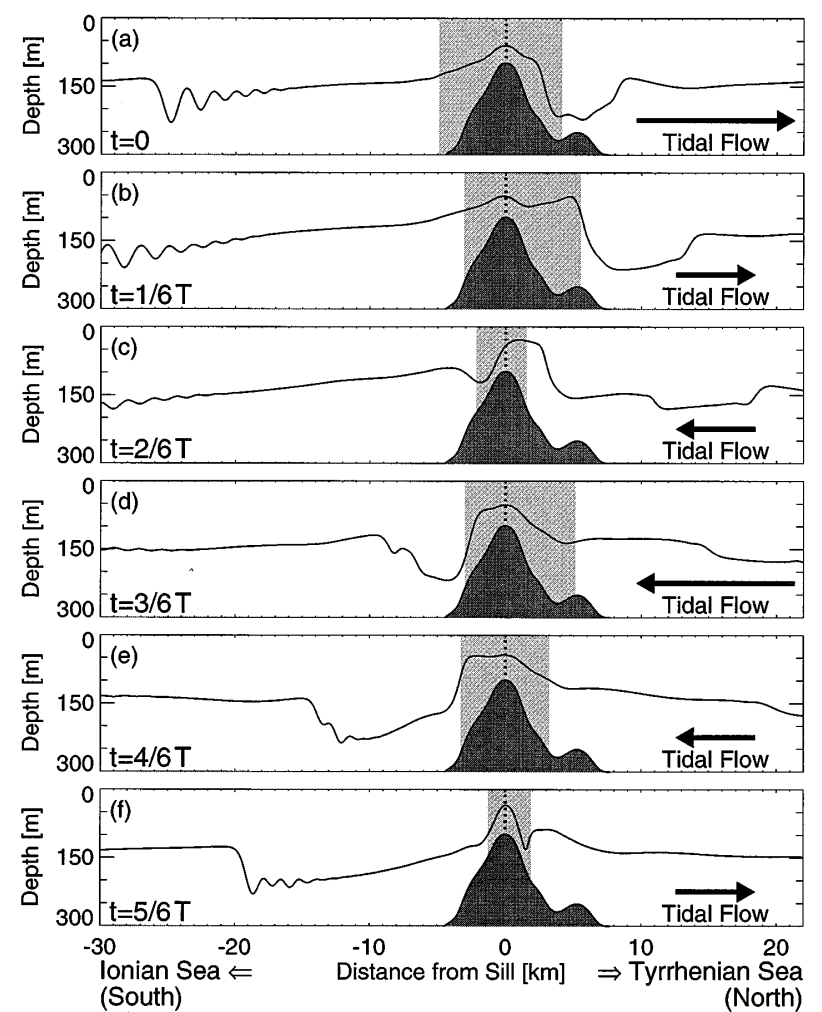

FIG. 18. Same as in Fig. 16 but for the case of no seasonal thermocline. The undisturbed interface depth is $150 \mathrm{~m}$ and the reduced gravity is $4.9 \times 10^{-3} \mathrm{~m} \mathrm{~s}^{-2}$. Here a depth range between 0 and 300 $\mathrm{m}$ is shown.

LIW, which are separated at a depth of $150 \mathrm{~m}$. The reduced gravity associated with this stratification is assumed to be $4.9 \times 10^{-3} \mathrm{~m} \mathrm{~s}^{-2}$. Our simulation yields the result that in the sill region the amplitudes of the total tidal transport, the tidal transport in the upper layer, and the tidal transport in the lower layer have the values $0.75,0.4$, and $0.25 \mathrm{~Sv}$ respectively. The mean transports in the upper and lower layer are $0.02 \mathrm{~Sv}$ into the Ionian Sea and $0.06 \mathrm{~Sv}$ into the Tyrrhenian Sea respectively.

Figure 18 shows the interface depth for six different times separated by $1 / 6$ of the tidal cycle with period $T$. The arrows indicates the direction and the strength of the tidal flow at the sill. The light gray shaded areas mark the regions where the composite Froude number $G$ is larger than 1. At maximum northward tidal flow, the interface at the sill is lifted upward, while north of the sill a strong interfacial depression is present (Fig. 18a). As long as the northward tidal flow persists, the depression north of the sill moves slightly northward (Fig. 18b). At slack water, the depression starts propagating southward. At maximum southward tidal flow (see Fig. 18d), the interfacial depression (internal bore) has already passed the sill. As discussed in section $6 \mathrm{~b}$, the internal bore disintegrates into a train of internal solitary waves. The number of solitary waves of the wave train increases with time (Figs. 18f, 18a, and 18b).
At maximum southward tidal flow (Fig. 18d), a strong interfacial depression develops south of the sill (onto which the southward propagating bore is now superimposed). At maximum northward tidal flow, this depression has passed the sill (Fig. 18a) and propagates northward. However, its shape is very smooth and cannot give birth to a train of internal solitary waves in the model domain (Figs. 18b and 18c).

In this case, the difference in the behavior of the southward and northward propagating internal waves cannot be ascribed only to the north-south asymmetry of the channel width. Here the north-south asymmetry of the depth profile plays an important role. As discussed for the amplitude-wavelength relationship of solitary waves (section 5b), for a very thick lower layer, as encountered south of the sill, nonlinear effects in the upper layer flow determine the steepening of the internal bore. For a thinner lower layer, as encountered north of the sill, nonlinear effects in the flow of such layer become important and tend to compensate nonlinear effects in the upper layer flow. As a consequence, the shape of the northward propagating internal bore is less steep.

In Fig. 19 the simulated surface convergence field is depicted in a space-time diagram for two tidal cycles. This space-time diagram clearly delineates the asymmetry of the convergence patterns north and south of the strait's sill. Whereas southward propagating internal waves are associated with alternating surface convergences and divergences, northward propagating internal waves are associated with a single weak surface convergence band.

At the end of this section, we want to discuss the necessity of using a generation model equipped with movable lateral boundaries, as the one we implemented for the present study. Actually, Fig. 18 shows that, in this simulation, the interface never intersects the bottom topography. Thus, for this particular case, the implementation of movable boundaries in the generation model is uniquely needed to prescribe, as initial condition, an undisturbed interface between the two water layers. Moreover, the result that the periodic solution does not show intersection between the interface and the bottom topography was a priori unknown.

\section{Discussion of the simulation results and comparison with ERS 1/2 SAR data}

In this section we discuss the results of our numerical simulations carried out by assuming different stratifications in the Strait of Messina and compare them with the results of our analysis of the available ERS 1/2 SAR data. Our numerical simulations show that our model can reproduce the time of release of the internal bores from the strait's sill (compare Fig. 4 with Figs. 17 and 19). However, the propagation speeds inferred from SAR observations of southward propagating internal waves are larger than the ones calculated with the model. The analysis of ERS 1/2 SAR data shows that in the 


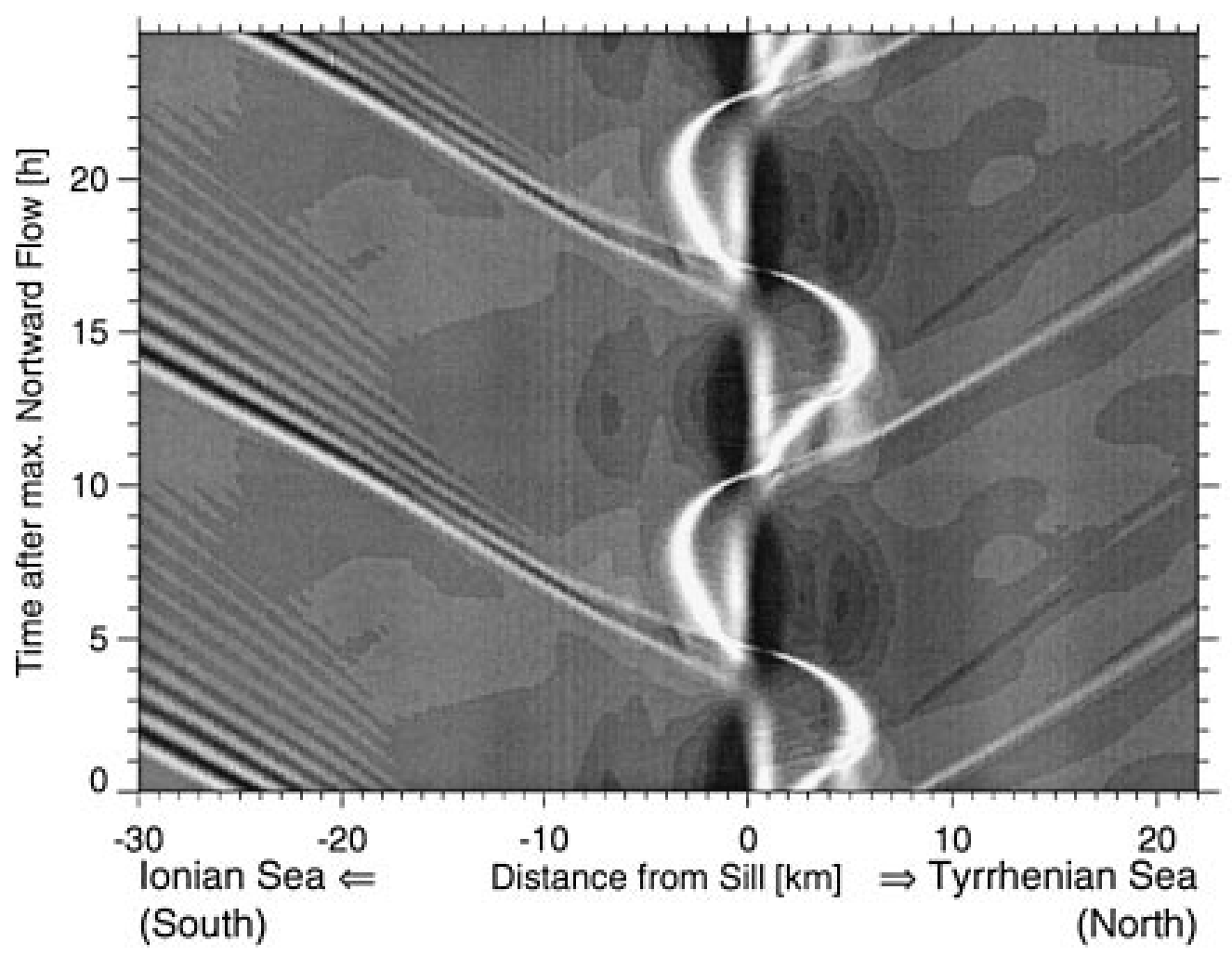

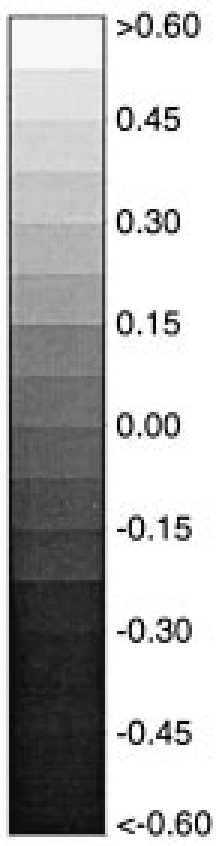

Convergence

Units: $10^{-3} \mathrm{~s}^{-1}$

FIG. 19. Same as in Fig. 17 but in the case of no seasonal thermocline. The undisturbed interface depth is $150 \mathrm{~m}$ and the reduced gravity is $4.9 \times 10^{-3} \mathrm{~m} \mathrm{~s}^{-2}$.

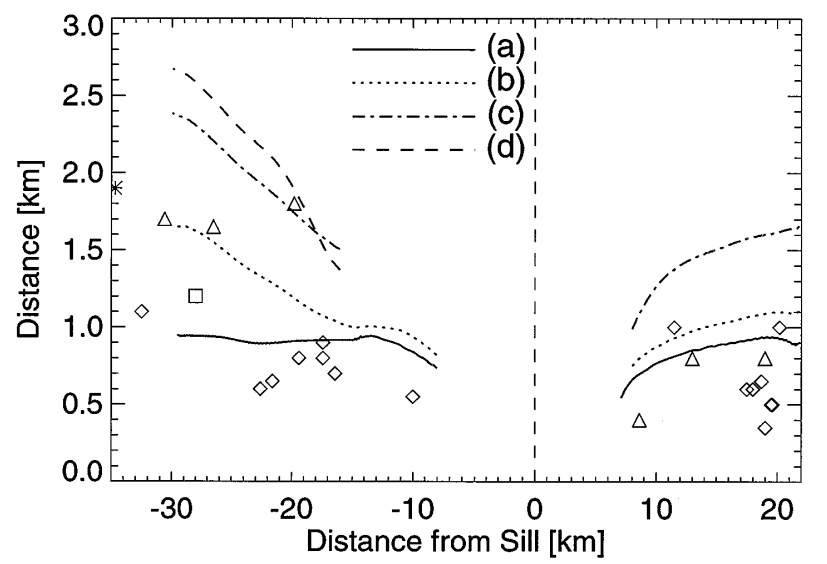

Ionian Sea $\Longleftarrow$ (South)

$\Rightarrow$ Tyrrhenian Sea (North)

FIG. 20. Spatial separation between the first two internal solitary waves in northward and southward propagating wave trains as a function of distance from the sill as inferred from ERS 1/2 SAR images. Diamonds refer to observations made between July and September, triangles to observations made between April and June, the square refers to an observation made between October and December, and the star to an observation made between January and March. Here curves are included that are obtained from numerical simulation with different values of the interface depth and the reduced gravity: (a) $H_{1}=15 \mathrm{~m}, g^{\prime}=19.6 \times 10^{-3} \mathrm{~m} \mathrm{~s}^{-2}$; (b) $H_{1}=30 \mathrm{~m}, g^{\prime}=14.7 \times$ $10^{-3} \mathrm{~m} \mathrm{~s}^{-2}$; (c) $H_{1}=90 \mathrm{~m}, g^{\prime}=4.9 \times 10^{-3} \mathrm{~m} \mathrm{~s}^{-2}$; and (d) $H_{1}=$ $150 \mathrm{~m}, g^{\prime}=4.9 \times 10^{-3} \mathrm{~m} \mathrm{~s}^{-2}$. period from July to September southward propagating internal waves propagate faster in the first $10 \mathrm{~km}$ far from the sill than in the region farther south (Fig. 4). The reason for this is that southward propagating internal bores, when they are released from the sill, are advected by the southward tidal flow, which is strong in the region close to the sill and weaker farther south. Our model reproduces this feature of the tidal flow in the Strait of Messina, but it seems to underestimate the advection of the internal bore with the tidal flow in the region close to the sill. This could be a consequence of the fact that we used in our model constant friction parameters. Their values were chosen large enough to avoid the generation of unrealistically large amplitude internal waves in the sill region (where actually strong turbulent mixing contributes to internal wave amplitude attenuation). However, larger friction parameters yield also a weaker tidal flow velocity in the sill region, which determines the wave advection. Thus, the propagation speeds predicted by the model must be smaller than the ones estimated from the analysis of SAR data. In the northern region, as well as in the southern region far from the sill, the tidal flow is weak because of the large channel width. In these regions the agreement between model and observation is much better.

Figure 20 shows the spatial separation between the first two internal solitary waves of northward and south- 
ward propagating wave trains as inferred from ERS 1/2 SAR data (Fig. 5) and as calculated with our numerical model. Numerical simulations were carried out for four different stratifications: (a) $H_{1}=15 \mathrm{~m}, g^{\prime}=19.6 \times$ $10^{-3} \mathrm{~m} \mathrm{~s}^{-2}$; (b) $H_{1}=30 \mathrm{~m}, g^{\prime}=14.7 \times 10^{-3} \mathrm{~m} \mathrm{~s}^{-2}$; (c) $H_{1}=90 \mathrm{~m}, g^{\prime}=4.9 \times 10^{-3} \mathrm{~m} \mathrm{~s}^{-2}$; and (d) $H_{1}=$ $150 \mathrm{~m}, g^{\prime}=4.9 \times 10^{-3} \mathrm{~m} \mathrm{~s}^{-2}$. While the stratifications assumed in simulations (b) and (d), which have been discussed in detail in the previous section, have been chosen as characteristic for a mean summer and winter stratification, the stratification in simulation (a) represents a situation in which an extremely strong seasonal thermocline is present and the stratification in simulation (c) represents a transition between mean summer and winter stratifications.

The model predicts, especially in the northern part of the Strait of Messina, larger spatial separations than observed by ERS 1/2 SAR. This could be a consequence of the fact that we have neglected in our model twodimensional radiation effects, like internal wave front curvature. Especially for northward propagating internal wave trains, the wave front curvature can vary strongly (compare Fig. 6 with Fig. 7). Actually, the simulated spatial separation between the first two internal solitary waves of northward propagating wave trains agrees quite well with the spatial separation as inferred from ERS 1/2 SAR data for those waves that show a small wave front curvature. Moreover, a comparison of model results with observations show that, while observed southward propagating internal wave trains are linked to a wide range of interface depths, observed northward propagating internal wave trains are only linked to a shallow interface depth. In fact, observations of southward propagating internal wave trains in the period from July to September reveal small spatial separations between the first two waves of an internal wave train. In this period a strong seasonal thermocline, characterized by a shallow interface and a strong density difference, is known to be present. On the other hand, observations of southward propagating internal wave trains during the period from October to June reveal larger spatial separations. This result is also obtained from the model if we assume an interface depth of $90 \mathrm{~m}$ and a reduced gravity of $4.9 \times 10^{-3} \mathrm{~m} \mathrm{~s}^{-2}$ (see Fig. 20). However, the latter choice of parameters yields simulated spatial separations between the first two waves of northward propagating internal wave trains that are not observed in ERS 1/2 SAR imagery. This is consistent with the observed absence of sea surface manifestations of northward propagating internal waves in ERS 1/2 SAR imagery in the period where a seasonal thermocline is known to be absent, that is, during winter (see Fig. 3). If we assume in our simulations an interface depth of $150 \mathrm{~m}$ (representing the stratification given by TSW and LIW), the spatial separations calculated with the model and inferred from the ERS 1/2 SAR data are not correlated. This, although not excluding the existence of such deep propagating internal waves, suggests that they are associated with a very weak surface convergence pattern that gives rise to a weak modulation of the surface roughness, which is not detectable by ERS 1/2 SAR.

\section{Summary and conclusions}

In this investigation we have presented a coupled twolayer numerical model capable of describing the generation and propagation of internal solitary waves in the Strait of Messina. The model is a composite of two models consisting of 1) a hydrostatic generation model equipped with movable lateral boundaries and 2) a weakly nonhydrostatic propagation model. The first model describes the dynamics of the water masses in the region close to the strait's sill where the internal bores are generated, and the second model describes the dynamics outside of the sill region where the internal bores disintegrate into trains of internal solitary waves. The generation model describes also the dynamics of a lower layer that may intersect the bottom topography by applying a technique for movable lateral boundaries. The validity of our model has been tested by comparing results of our model with results of other models and with laboratory data.

Internal waves in the Strait of Messina are generated by the interaction of the tidal flow with the shallow sill. Strong interfacial depressions are generated north (south) of the sill during northward (southward) tidal flow, which give rise to southward (northward) propagating internal bores that may disintegrate into trains of internal solitary waves.

The large amount of available ERS 1/2 SAR images acquired over the Strait of Messina and the adjacent sea areas has enabled us to perform, for the first time, a systematic analysis of the internal wave field in this region. From this analysis several peculiarities of the internal wave field in the Strait of Messina have emerged: 1) northward as well as southward propagating internal waves are generated in the Strait of Messina, 2) southward propagating internal waves are observed more frequently than northward propagating internal waves, 3) sea surface manifestations of southward as well as northward propagating internal waves are stronger during periods where a strong seasonal thermocline is known to be present, 4) southward propagating internal bores are released from the sill between 1 and 5 hours after maximum northward tidal flow at Punta Pezzo, northward propagating internal bores are released between 2 and 6 hours after maximum southward tidal flow at Punta Pezzo, and 5) the spatial separation between the first two internal solitary waves of southward propagating wave trains is smaller in the period from July to September than in the period from October to June.

Simulations carried out with different values of the interface depth and the reduced gravity show that simulated surface convergence patterns are stronger in the case of a shallow interface with a strong density dif- 
ference than in the case of a deep interface with a weak density difference. Our model can explain the northsouth asymmetry of the internal wave field. This asymmetry is the result of the north-south asymmetry of the topography of the Strait of Messina: the water depth is shallower and the channel width is larger north of the sill than south of it. Thus, southward propagating internal waves are stronger than northward propagating ones. A comparison of the spatial separation between the first two solitary waves of an internal wave train calculated with the model and inferred from ERS 1/2 SAR data shows that observed southward propagating internal solitary waves are linked to a wide range of interface depths, while observed northward propagating internal solitary waves are only linked to a shallow interface depth.

ERS 1/2 SAR images show a large variability in the sea surface manifestations of northward propagating internal waves. The shape of the internal wave pattern, their wavelength, as well as the modulation depth vary considerably. This variability could result from strong turbulences that are known to be present north of the sill, their most famous manifestations being perhaps the once terrifying whirls of Scylla and Charybdis (Defant 1940).

Acknowledgments. We thank ESA for supplying the ERS 1/2 SAR data. This work was supported by the German Space Agency (DARA), under Contract 50 EE 9413.

\section{REFERENCES}

Alpers, W., 1985: Theory of radar imaging of internal waves. Nature, 314, 245-247.

—, and E. Salusti, 1983: Scylla and Charybdis observed from space. J. Geophys. Res., 88, 1800-1808.

Androsov, A. A., N. Ye. Vol'tsinger, B. A. Kagan, and E. Salusti, 1994: Residual tidal circulation in the Strait of Messina. Phys. Atmos. Ocean, 29, 522-531.

Apel, J. R., H. M. Byrne, J. R. Proni, and R. L. Charnell, 1975: Observations of oceanic internal waves from the Earth Resources Technology Satellite. J. Geophys. Res., 80, 865-881.

— J. R. Holbrook, J. Tsai, and A. K. Liu, 1985: The Sulu Sea internal soliton experiment. J. Phys. Oceanogr., 15, 1625-1651.

_ L. A. Ostrovsky, and Y. A. Stepanyants, 1995: Internal solitons in the ocean. Tech. Rep. MERCJRA0695, 70 pp. [Available from Milton S. Eisenhower Research Center, Applied Physics Laboratory, The Johns Hopkins University, Johns Hopkins Rd., Laurel, MD 20707.]

Artale, V., D. Levi, S. Marullo, and R. Santoleri, 1990: Analysis of nonlinear internal waves observed by Landsat thematic mapper. J. Geophys. Res., 95, 16 065-16 073.

Backhaus, J. O., 1976: Zur Hydrodynamik im Flachwassergebiet, ein numerisches Modell. Dtsch. Hydrogr. Z., 29, 222-238.

Baines, P. G., 1984: A unified description of two-layer flow over topography. J. Fluid Mech., 146, 127-167.

Benjamin, T. B., 1966: Internal waves of finite amplitude and permanent form. J. Fluid Mech., 25, 97-116.

- 1967: Internal waves of permanent form in fluids of great depth. J. Fluid Mech., 29, 559-592.

Benny, D. J., 1966: Long non-linear waves in fluid flows. J. Math. Phys., 45, 52-63.
Bignami, F., and E. Salusti, 1990: Tidal currents and transient phenomena in the Strait of Messina: A review. The Physical Oceanography of Sea Straits, L. J. Pratt, Ed., Kluwer Academic, 95124.

Brandt, P., W. Alpers, and J. O. Backhaus, 1996: Study of the generation and propagation of internal waves in the Strait of Gibraltar using a numerical model and synthetic aperture radar images of the European ERS 1 satellite. J. Geophys. Res., 101, 14 237-14 252.

Defant, A., 1940: Scylla und Charybdis und die Gezeitenströmungen in der Strasse von Messina. Annalen der Hydrographie und Maritimen Meteorologie, 5, 145-157. , 1961: Physical Oceanography. Vol. 2. Pergamon, 598 pp.

Del Ricco, R., 1982: A numerical model of the vertical circulation of tidal strait and its application to the Messina Strait. Nuovo Cimento Soc. Ital. Fis., 5C, 21-45.

Di Sarra, A., A. Pace, and E. Salusti, 1987: Long internal waves and columnar disturbances in the Strait of Messina. J. Geophys. Res., 92, 6495-6500.

Djordjevic, V. D., and L. G. Redekopp, 1978: The fission and disintegration of internal solitary waves moving over two-dimensional topography. J. Phys. Oceanogr., 8, 1016-1024.

Fu, L. L., and B. Holt, 1984: Internal waves in the Gulf of California: Observations from a spaceborne radar. J. Geophys. Res., 89, 2053-2060.

Gerkema, T., and J. T. F. Zimmerman, 1995: Generation of nonlinear internal tides and solitary waves. J. Phys. Oceanogr., 25, 10811094.

Griffa, A., S. Marullo, R. Santolieri, and A. Viola, 1986: Preliminary observations of large-amplitude tidal internal waves near the Strait of Messina. Contin. Shelf Res., 6, 677-687.

Halpern, D., 1970: Semidiurnal tides in Massachusetts Bay. J. Geophys. Res., 76, 6573-6584.

Hibiya, T., 1986: Generation mechanism of internal waves by tidal flow over a sill. J. Geophys. Res., 91, 7697-7708.

_ 1990: Generation mechanism of internal waves by a vertically sheared tidal flow over a sill. J. Geophys. Res., 95, 1757-1764.

Hopkins, T. S., E. Salusti, and D. Settimi, 1984: Tidal forcing of the water mass interface in the Strait of Messina. J. Geophys. Res., 89, 2013-2024.

Jungclaus, J. H., and J. O. Backhaus, 1994: Application of a transient reduced-gravity plume model to the Denmark Strait overflow. $J$. Geophys. Res., 99, 12 375-12 396.

Keulegan, G. H., 1953: Characteristics of internal solitary waves. $J$. Res. Nat. Bur. Stand., 51, 133-140.

Koop, C. G., and G. Butler, 1981: An investigation of internal solitary waves in a two-fluid system. J. Fluid Mech., 112, 225-251.

Korteweg, D. J., and G. de Vries, 1895: On the change of form of long waves advancing in a rectangular canal, and on a new type of long stationary waves. Philos. Mag., 39, 422-443.

Lansing, F. S., and T. Maxworthy, 1984: On the generation and evolution of internal gravity waves. J. Fluid Mech., 145, 127-149.

Liu, A. K., 1988: Analysis of nonlinear internal waves in the New York Bight. J. Geophys. Res., 93, 12 317-12 329.

Long, R. R., 1954: Some aspects of the flow of stratified fluids, II. Experiments with a two-layer system. Tellus, 6, 97-115.

_ 1956: Solitary waves in one and two-fluid system. Tellus, 8 , 460-471.

Longo, A., M. Manzo, and S. Pierini, 1992: A model for the generation of nonlinear internal tides in the Strait of Gibraltar. Oceanol. Acta, 15, 233-243.

Maxworthy, T., 1979: A note on the internal solitary waves produced by tidal flow over a three-dimensional ridge. J. Geophys. Res., 84, 338-346.

_ 1980: On the formation of nonlinear internal waves from the gravitational collapse of mixed regions in two and three dimensions. J. Fluid Mech., 96, 47-64.

Miles, J. W., 1979: On internal solitary waves. Tellus, 31, 456-462. Miyata, M., 1988: Long internal waves of large amplitude. Nonlinear 
Water Waves, K. Horikawa and H. Maruo, Eds., Springer-Verlag, 399-406.

New, A. L., and R. D. Pingree, 1992: Local generation of internal soliton packets in the central Bay of Biscay. Deep-Sea Res., 39, $1521-1534$.

Nicolò, L., and E. Salusti, 1991: Field and satellite observations of large amplitude internal tidal wave trains south of the Strait of Messina, Mediterranean Sea. Ann. Geophys., 9, 534-539.

Oğuz, T., E. Özsoy, M. A. Latif, H. I. Sur, and Ü. Ünlüata, 1990: Modeling of hydraulically controlled exchange flow in the Bosphorus Strait. J. Phys. Oceanogr., 20, 945-965.

Ono, H., 1975: Algebraic solitary waves in stratified fluids. J. Phys. Soc. Japan, 39, 1082-1091.

Orlanski, I., 1976: A simple boundary condition for unbounded hyperbolic flows. J. Comput. Phys., 21, 251-269.

Osborne, A. R., and T. I. Burch, 1980: Internal solitons in the Andaman Sea. Science, 208, 451-460.

Pierini, S., 1989: A model for the Alboran Sea internal solitary waves. J. Phys. Oceanogr., 19, 755-772.

Pingree, R. D., and G. T. Mardell, 1985: Solitary internal waves in the Celtic Sea. Progress in Oceanography, Vol. 14, Pergamon, 431-441.
Renouard, D. P., and J. M. Baey, 1993: Two experimental studies of internal waves generated by tide-topography interaction. Dyn. Atmos. Oceans, 19, 205-232.

Richez, C., 1994: Airborne synthetic aperture radar tracking of internal waves in the Strait of Gibraltar. Progress in Oceanography, Vol. 33, Pergamon, 93-159.

Sandstrom, H., and J. A. Elliot, 1984: Internal tide and solitons on the Scotian Shelf: A nutrient pump at work. J. Geophys. Res., 89, 6415-6426.

Sapia, A., and E. Salusti, 1987: Observation of nonlinear internal solitary wave trains at the northern and southern mouths of the Strait of Messina. Deep-Sea Res., 34, 1081-1092.

Vercelli, F., 1925: Il regime dello correnti e delle maree nello stretto di Messina. Commissione Internazionale del Mediterraneo, negli Anni 1922 e 1923, 209 pp.

Watson, G., and I. S. Robinson, 1990: A study of internal wave propagation in the Strait of Gibraltar using shore-based marine radar images. J. Phys. Oceanogr., 20, 374-395.

Woodward, P., and P. Colella, 1984: The numerical simulation of twodimensional fluid flow with strong shocks. J. Comput. Phys., 54, 115-173.

Ziegenbein, J., 1969: Short internal waves in the Strait of Gibraltar. Deep-Sea Res., 16, 479-487. 